\title{
Evaluation of Articular Eminence Morphology and Inclination in TMJ Internal Derangement Patients with MRI
}

\author{
Evaluación de la Morfología e Inclinación de la Eminencia Articular \\ en Pacientes con Trastorno Interno de ATM con MRI \\ "Aydin Ozkan; **Hasan Ayberk Altug; ${ }^{* * *}$ Metin Sencimen \& ${ }^{* * * * *}$ Bugra Senel
}

OZKAN, A., ALTUG, H. A.; SENCIMEN, M. \& SENEL, B. Evaluation of articular eminence morphology and inclination in TMJ internal derangement patients with MRI. Int. J. Morphol., 30(2):740-744, 2012.

SUMMARY: Articular eminence morphology and inclination are reported to be two predisposing factors for the internal derangement (ID). The purpose of this study is to investigate the relationship between the inclination and morphology of the articular eminence and ID. The study included 70 temporomandibular joints with ID in 35 patients: 51 joints had disc displacements with reduction (DDWR) and 19 joints had disc displacements without reduction (DDWOR). All subjects underwent bilateral high resolution magnetic resonance imaging scans which were performed in the sagittal and coronal planes with mouths closed and opened. Articular eminence morphology was characterized as box, sigmoid, flattened, or deformed. Articular eminence inclination was measured at three positions: steep (from $60^{\circ}$ to $90^{\circ}$ ), moderate (from $30^{\circ}$ to $60^{\circ}$ ) and shallow (from $15^{\circ}$ to $30^{\circ}$ ). The images were divided into two; DDWR and DDWOR, and these two criteria were compared. The images of the two groups were compared; while flattened form was occurred with the highest incidence in the DDWOR group, sigmoid form was the most frequent in the DDWR group and articular eminence inclination was found steeper than it was for the DDWOR group. The steepness of the articular eminence may not have a predisposing effect on the development of disc displacements.

KEY WORDS: Articular Eminence; Internal Derangement; Magnetic Resonance Imaging.

\section{INTRODUCTION}

Magnetic resonance imaging (MRI) is a major development in the field of medical imaging due to its unique technology and the precision this technology provides in both soft and hard tissue imaging. It is considered as the choice of imaging technique for the evaluation of the temporomandibular joint (TMJ) and in the diagnosis of internal derangement (ID), both displacements with reduction (DDWR) and without reduction (DDWOR), with its high degree of accuracy (Katzberg et al., 1985).

ID of the TMJ, the most common type of temporomandibular disorders, has been defined as an abnormal positional relationship among the disc and condyle, articular eminence, and/or articular fossa (Murakami et al., 1993). Although articular eminence morphology was stated as an aetiological factor in the development of TMJ ID in several articles (Hall et al., 1985; Sato et al., 1999; Sülün et al., 2001), there are authors who did not support these results too (Galante et al., 1995; Ren et al., 1995; Kinniburgh et al., 2000; Kurita et al., 2000a.). Additionally, it is argued that articular eminence flattening can be a result of internal disorders (Kurita et al., 2000b; Emshoff et al., 2003).

The normal value of articular eminence angle in adults has been reported to be $30^{\circ}-60^{\circ}$. Articular eminences having inclination values smaller than $30^{\circ}$ have been characterized as flat, and those having values greater than $60^{\circ}$ have been characterized as steep (Katsavrias, 2002).

The disc should rotate forward over the condyle to maintain the correct relationship during the movements. When the articular eminence is steeper than normal, the condyle is forced to move inferiorly as it shifts anteriorly. This situation causes a greater vertical movement of the condyle, mandible, and mandibular arch upon opening, and this movement might lead to the loosening of the ligaments attaching the disc to the condyle (Okeson, 1998).

* DDS, PhD, Diyarbakır Military Hospital, Department of Oral\&Maxillofacial Surgery, Diyarbakır, Turkey.

** DDS, PhD, Gulhane Military Medical Academy, Department of Oral \& Maxillofacial Surgery, Ankara, Turkey.

*** Assistant Professor, Gulhane Military Medical Academy, Department of Oral\&Maxillofacial Surgery, Ankara, Turkey.

***** DDS, PhD, Diyarbakır Military Hospital, Department of Oral\&Maxillofacial Radiology, Diyarbakır, Turkey. 
The aim of this retrospective study was to investigate the morphology and inclination of the articular eminence in patients with DDWR and DDWOR.

\section{MATERIAL AND METHOD}

Participants. The study protocol was approved by the Research Ethics Committee, Gülhane Military Medical Academy, Ankara, Turkey. The investigation was based on a retrospective study of 35 selected patients ( 17 females, 18 males) with signs and symptoms of ID. Their mean age was 45,4 . The sample consisted of 70 joints with disc displacement; 51 DDWR and 19 DDWOR.

Experimental protocol. Bilateral high-resolution MRI scans were made for all subjects with a Philips Gyroscan ACS - II 1.5 Tesla (Philips Medical Systems, Best, Netherlands) in the closed-mouth and maximum opening positions. The images were obtained in T1 (TR 500, TE 15) with 3-mm oblique-sagittal slices with no spacing.

Articular eminence morphology was classified into four types, according to the criteria set by Kurita et al.: box, sigmoid, flattened or deformed. The box shape represents a larger articular eminence or a deeper articular fossa than sigmoid shapes, while the sigmoid shape represents a larger articular eminence or a deeper articular fossa than flattened shapes. In short, while the box shape is the deepest, the flattened shape is the shallowest (Fig. 1).

Articular eminence inclination was measured as three positions: steep (from $60^{\circ}$ to $90^{\circ}$ ), moderate (from $30^{\circ}$ to $60^{\circ}$ ) and shallow (from $15^{\circ}$ to $30^{\circ}$ ). The technique for measuring the inclination of the eminence was shown in Fig. 2. Reference lines were drawn at the close-mouth positions on the MRI. The most cranial point on curvature of glenoid fossa (f) was identified and a horizontal reference line was established as the tangent to this point and parallel to the

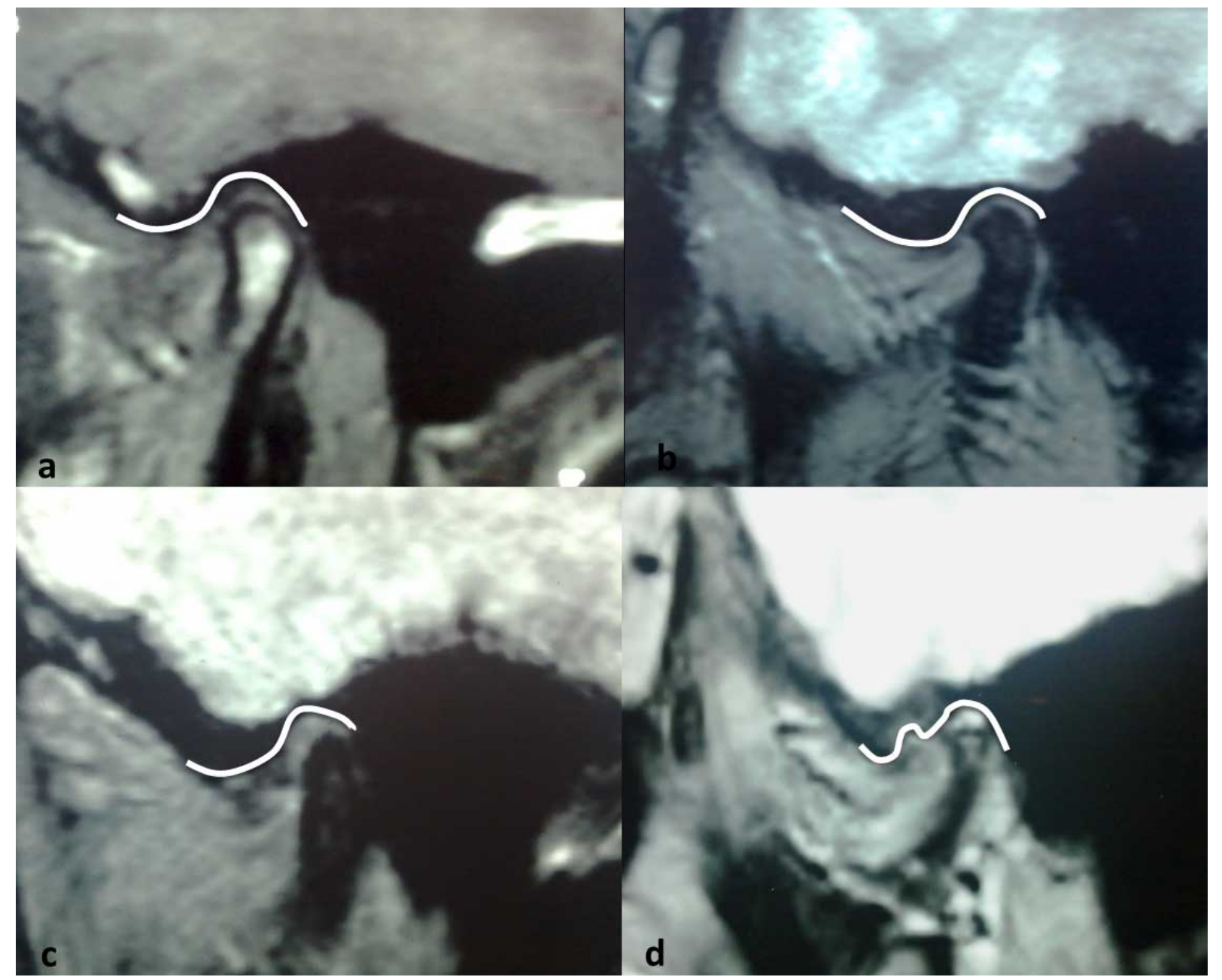

Fig. 1. Classification of articular eminence shapes: (A) box, (B) sigmoid, (C) flattened and (D) deformed. 
horizontal plane of MRI, because of this, it became parallel to the Frankfort horizontal (FH) plane. The highest point of condyle (c) was joined with a line to intersect with the posterior slope of eminence (a) and then another line was drawn from this point to become tangent to posterior surface of articular eminence. These two lines formed an angle (e). This angle presented a measure of articular eminence inclination.

Statistics. The samples were divided into two groups of DDWR and DDWOR. The exact Fisher test was used to evaluate differences in the distribution of shapes. The Mann-Whitney Utest was used to compare the mean among the measurements of the inclination of the eminence.

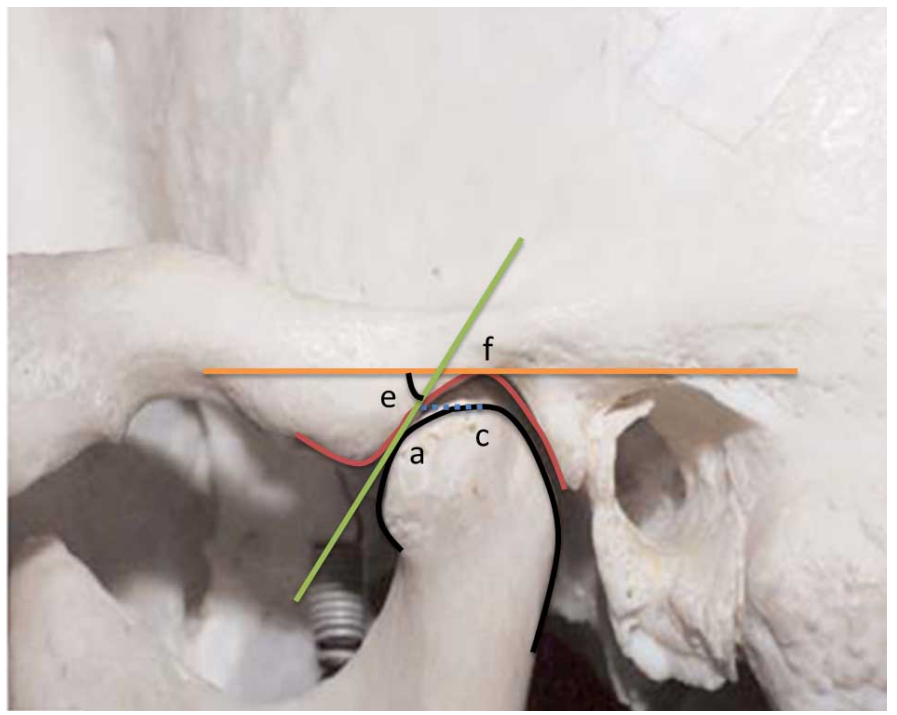

Fig. 2. Measurement of the inclination of the eminence on MRI. The most cranial point on curvature of glenoid fossa (f) was identified and a horizontal reference line was established as the tangent to this point and parallel to the horizontal plane of MRI, because of this, it became parallel to the Frankfort horizontal (FH) plane. The highest point of condyle (c) was joined with a line to intersect with the posterior slope of eminence (a), then another line was drawn from this point to become tangent to posterior surface of articular eminence. These two lines formed an angle (e). This angle presented a measure of articular eminence inclination.

\section{RESULTS}

The results of the classification of articular eminence shape are shown in Table I. The flattened shape was the most frequent in the group without reduction (p: 0.000). The sigmoid form presented the greatest incidence, followed by the box form, in the DDWR group.

The means, standard deviations and ranges for each variable are shown in Table II. The mean inclination of the eminence was 43.13 degrees (range, 21 to 65 degrees) in the DDWR group, and the mean inclination of the eminence was 30.55 degrees (range, 22 to 62 degrees) in the DDWOR group. A statistically significant correlation was not found between the steepness of the groups, but when the mean inclination was compared, it was identified that the mean inclination of DDWR group was higher.

The distributions of articular eminence angular positions are presented in Table III. In both groups, moderate (from $30^{\circ}$ to $60^{\circ}$ ) position was the most frequent, followed by shallow (from $15^{\circ}$ to $30^{\circ}$ ) and steep (from $60^{\circ}$ to $90^{\circ}$ ) positions.

\section{DISCUSSION}

Many radiographic methods have been used in previous studies to measure the inclination of the posterior slope of the articular eminence. The method is a very important factor, as it influences the results. Kerstens et al. (1989) used panoramic radiography, which only depicted the most lateral part of the articular eminence. Panoramic radiographs of the joint are distorted, making it very difficult to accurately and reliably interpret its morphology (Hintze et al., 2009). Galante et al., Kurita et al., Sülün et al. and Major et al. (2002) used MRI which has the advantage of diagnosing disc position. MRI allows a tridimensional analysis of the TMJ, providing the most complete assessment of the relationship of the mandibular head, articular disc, mandibular fossa and articular eminence (Hasso et al., 1989). Therefore, MRI was chosen for our study.

In this study, the articular eminence shape was classified into four groups according to the criteria presented by Kurita et al. As in our results, those authors observed a trend towards a more sigmoid shape, followed by the box shape in DDWR, although it was not statistically significant. In DDWOR, they found a significant difference in the prevalence of the flattened shape. We also found a statistically significant difference in the distribution of the flattened shape between DDWOR and DDWR (Table I).

Gökalp et al. (2001) found that the articular eminence inclination was higher in patients with DDWR than in patients with DDWOR. In this study, we mostly found similar results, but we found moderate position as high incidence in the both sides when we compared them as for angular positions.

The biomechanical theory of disc displacement postulates that, with a steep eminence, there is a tendency 
Table I. Distribution of the articular eminence shapes for the groups with disc displacement with reduction (DDWR) and without reduction (DDWOR).

\begin{tabular}{cccc}
\hline Eminence & DDWR & DDWOR & \\
\cline { 2 - 3 } Shapes & $\mathrm{N}(\%)$ & $\mathrm{N}(\%)$ & P values \\
\hline Box & $19(37.3)$ & $5(26.3)$ & $*(0.03)$ \\
Sigmoid & $28(54.9)$ & $3(15.8)$ & $*(0.003)$ \\
Flattered & $1(2)$ & $8(42.1)$ & $*(0.000)$ \\
Deformed & $3(5.9)$ & $3(15.8)$ & $* *(0.196)$ \\
\hline
\end{tabular}

The exact Fisher test is used to statistical analyses. $\mathrm{n}=$ sample $*$ statistically significant $* *$ not significant.

Table II. Compare the mean among the measurements of the eminence inclination. The Mann-Whitney U-test is used to statistical analyses.

\begin{tabular}{cccccc}
\hline \multirow{2}{*}{$\begin{array}{c}\text { Internal } \\
\text { Derangement }\end{array}$} & \multicolumn{5}{c}{ Eminence Inclination } \\
\cline { 2 - 6 } & MIN. & MAX. & MED. & MEAN & ST.DEV. \\
\hline DDWR & 21 & 65 & 42 & 43,13 & 10,72 \\
DDWOR & 22 & 62 & 31 & 30,55 & 5,36 \\
TOTAL & 21 & 65 & 42,5 & 43,4 & 11,62 \\
\hline
\end{tabular}

Table III. The distributions of angular positions of the articular eminence.

\begin{tabular}{cccc}
\hline Internal & \multicolumn{3}{c}{ Eminence Inclination } \\
\cline { 2 - 4 } Derangement & SHALLOW & MODERATE & STEEP \\
\hline DDWR & 5 & 43 & 3 \\
DDWOR & 4 & 12 & 3 \\
TOTAL & 9 & 55 & 6 \\
\hline
\end{tabular}

for the disc to rotate farther forward than normal on the condyle as the disccondyle assembly rotates forward within the glenoid fossa during mouth opening. Meanwhile there is a stabilizing force produced by the masseter and temporalis, which with a steeper eminence, places a greater relative distalizing force relative to the disc (Atkinson \& Bates, 1983; Isberg \& Westesson, 1998). This might result in laxity of the ligaments that attach the disc to the condyle (Perrini et al., 1997; Deodato et al., 2006). The disc articulating against a steep eminence during mouth opening would gradually achieve a more anterior position relative to the condyle, predisposing the disc to anterior displacement (Isberg \& Westesson).

Some studies considered articular eminence flattening as a secondary result to ID. The steepness of articular eminence decreased in the progressive ID as a result of remodeling or degenerative changes of the bone (Sülün et al.; Kurita et al.). Yamada et al. (2004) suggested that flattening of the eminence had seemed to occur during changes from erosion to osteophyte and from DDWR to DDWOR. It seems that condyle, articular disc and eminence might respond adaptively to loading in the TMJ. Articular eminence can be seen as a result of degenerative changes secondary to ID.

CONCLUSIONS. In the ID of the TMJ, the articular eminence morphology is highly variable and it differs interindividually.
Although the mean inclination of the eminence in the DDWR sides are found higher than the mean inclination of the eminence in the DDWOR sides, when DDWR and DDWOR sides are evaluated for angular positions, moderate position is found the highest in number in the both sides.

Morphologically, the flattened shapes are the most frequent on the sides without reduction, because of this reason; ID can lead to the degenerative changes on the articular eminence.

As a result because there is no significant difference in inclination between the DDWR and DDWOR sides, height of the articular eminence may not have a predisposing factor for the ID of TMJ.

OZKAN, A., ALTUG, H. A.; SENCIMEN, M. \& SENEL, B. Evaluación de la morfología e inclinación de la eminencia articular en pacientes con trastorno interno de ATM con MRI. Int. J. Morphol., 30(2):740-744, 2012.

RESUMEN: La morfología e inclinación de la eminencia articular son reportados como dos factores predisponentes para el trastorno interno (TI). El propósito de este estudio fue investigar la relación entre la inclinación y la morfología de la eminencia articular y el TI. El estudio incluyó a 70 articulaciones temporomandibulares, con TI en 35 pacientes: 51 articulaciones con desplazamiento discal con reducción (DDCR) y 19 de las articulaciones tuvieron desplazamiento discal sin reducción (DDSR). Todos los sujetos fueron sometidos a imágenes de resonancia magnética bilaterales de alta resolución que se realizaron en los planos sagital y coronal con la boca cerrada y abierta. La morfología articular la eminencia se caracterizó como una caja, sigmoide, aplanada, o deforme. La inclinación de la eminencia articular se midió en tres posiciones: empinada ( de $60^{\circ}$ a $90^{\circ}$ ), moderada (entre $30^{\circ}$ a $60^{\circ}$ ) y poco profunda (entre $15^{\circ}$ y $30^{\circ}$ ). Las imágenes fueron divididos en dos; DDCR y DDSOR, y estos criterios fueron comparados. Al comparar las imágenes de ambos grupos, la forma aplanada se observó con mayor incidencia en el grupo de DDSR, la forma sigmoide fue la más frecuente en el grupo de DDCR y la inclinación de la eminencia articular se encontró más pronunciada que en el grupo DDSR. La inclinación de la eminencia articular puede no tener un efecto predisponente en el desarrollo de los desplazamientos de disco.

PALABRAS CLAVE: Eminencia articular; Trastornos internos; Resonancia magnética. 


\section{REFERENCES}

Atkinson, W. B. \& Bates R. E, Jr. The effects of the angle of the articular eminence on anterior disk displacement. J. Prosthet. Dent., 49(4):554-5, 1983.

Deodato, F.; Trusendi, R.; Giorgetti, R. \& Scalese, M. U. Predisposition for temporomandibular joint disorders: loose ligaments. Cranio, 24(3):179-83, 2006

Emshoff, R.; Brandlmaier, I.; Bertram, S. \& Rudisch A. Risk factors for temporomandibular joint pain in patients with disc displacement without reduction - a magnetic resonance imaging study. J. Oral Rehabil., 30(5):537-43, 2003.

Galante, G.; Paesani, D.; Tallents, R. H.; Hatala, M. A; Katzberg, R. W. \& Murphy, W. Angle of the articular eminence in patients with temporomandibular joint dysfunction and asymptomatic volunteers. Oral Surg. Oral Med. Oral Pathol. Oral Radiol. Endod., 80(2):2429, 1995.

Gökalp, H.; Türkkahraman, H. \& Bzeizi, N. Correlation between eminence steepness and condyle disc movements in temporomandibular joints with internal derangements on magnetic resonance imaging. Eur. J. Orthod., 23(5):579-84, 2001.

Hall, M. B.; Gibbs, C. C. \& Sclar, A. G. Association between the prominence of the articular eminence and displaced TMJ disks. Cranio, 3(3):237-9, 1985.

Hasso, A. N.; Christiansen, E. L. \& Alder, M. E. The temporomandibular joint. Radiol. Clin. North Am., 27(2):301-14, 1989.

Hintze, H.; Wiese, M. \& Wenzel, A. Comparison of three radiographic methods for detection of morphological temporomandibular joint changes: panoramic, scanographic and tomographic examination. Dentomaxillofac. Radiol., 38(3):134-40, 2009.

Isberg, A. \& Westesson, P. L. Steepness of articular eminence and movement of the condyle and disk in asymptomatic temporomandibular joints. Oral Surg. Oral Med. Oral Pathol. Oral Radiol. Endod., 86(2):152-7, 1998.

Katsavrias, E. G. Changes in articular eminence inclination during the craniofacial growth period. Angle Orthod., 72(3):258-64, 2002.

Katzberg, R. W.; Schenck, J.; Roberts, D., Tallents, R. H.; Manzione, J. V.; Hart, H. R.; Foster, T. H.; Wayne, W. S. \& Bessette, R. W. Magnetic resonance imaging of the temporomandibular joint meniscus. Oral Surg. Oral Med. Oral Pathol., 59(4):332-5, 1985.

Kerstens, H. C.; Tunzing, D. B.; Golding, R. P. \& Van der Kwast, W. A. Inclination of the temporomandibular joint eminence and anterior disc displacement. Int. J. Oral Maxillofac. Surg., 18(4):228-32, 1989.

Kinniburgh, R. D.; Major, P. W.; Nebbe, B.; West, K. \& Glover, K. E. Osseous morphology and spatial relationships of the temporomandibular joint: comparisons of normal and anterior disc positions. Angle Orthod., 70(1):70-80, 2000.
Kurita, H.; Ohtsuka, A.; Kobayashi, H. \& Kurashina, K. Is the morphology of the articular eminence of the temporomandibular joint a predisposing factor for disc displacement? Dentomaxillofac. Radiol., 29(3):159-62, 2000a.

Kurita, H.; Ohtsuka, A.; Kobayashi, H. \& Kurashina, K. Flattening of the articular eminence correlates with progressive internal derangement of the temporomandibular joint. Dentomaxillofac. Radiol., 29(5):277-9, 2000b.

Major, P. W.; Kinniburgh, R. D.; Nebbe, B.; Prasad, N. G. \& Glover, K. E. Tomographic assessment of temporomandibular joint osseous articular surface contour and spatial relationships associated with disc displacement and disc length. Am. J. Orthod. Dentofacial Orthop., 121(2):152-61, 2002.

Murakami, S.; Takahashi, A.; Nishiyama, H.; Fujishita, M. \& Fuchihata, $\mathrm{H}$. Magnetic resonance evaluation of the temporomandibular joint disc position and configuration. Dentomaxillofac. Radiol., 22(4):205-7, 1993.

Okeson, J. P. Management of Temporomandibular Disorders and Occlusion. 4th Ed. St. Louis, Mosby-Year Book, 1998.

Perrini, F.; Tallents, R. H.; Katzberg, R. W.; Ribeiro, R. F.; Kyrkanides, S. \& Moss M. E. Generalized joint laxity and temporomandibular disorders. J. Orofac. Pain, 11(3):215-21, 1997.

Ren, Y. F.; Isberg, A. \& Westesson, P. L. Steepness of the articular eminence in the temporomandibular joint. Tomographic comparison between asymptomatic volunteers with normal disk position and patients with disk displacement. Oral Surg. Oral Med. Oral Pathol. Oral Radiol. Endod., 80(3):258-66, 1995.

Sato, S.; Sakamoto, M.; Kawamura, H. \& Motegi, K. Long-term changes in clinical signs and symptoms and disc position and morphology in patients with nonreducing disc displacement in the temporomandibular joint. J. Oral Maxillofac. Surg., 57(1):23-30, 1999.

Sülün, T.; Cemgil, T.; Duc, J. M.; Rammelsberg, P.; Jäger, L. \& Gernet, W. Morphology of the mandibular fossa and inclination of the articular eminence in patients with internal derangement and in symptom-free volunteers. Oral Surg. Oral Med. Oral Pathol. Oral Radiol. Endod., 92(1):98-107, 2001.

Yamada, K.; Tsuruta, A.; Hanada, K. \& Hayash1, T. Morphology of the articular eminence in temporomandibular joints and condylar bone change. J. Oral Rehabil., 31(5):438-44, 2004.

\section{Correspondence to: \\ Aydin Ozkan, DDS, PhD \\ Diyarbakır Military Hospital \\ Yenisehir 21100 \\ Diyarbakır \\ TURKEY}

Email: ydnozkan@yahoo.com

Received: 19-12-2011

Accepted: 06-03-2012 